\title{
LA CONSTRUCCIÓN ARTÍSTICA DEL ESPACIO INDÍGENA Y LOS PAISAJES ITINERANTES
}

\section{THE ARTISTIC CONSTRUCTION OF INDIGENOUS SPACE AND ITINERANT LANDSCAPES}

\author{
Elisa Garrido \\ (Universidad Autónoma de Madrid, España) \\ elisa.garrido.moreno@uam.es
}

Recibido: 23 de abril 2020 / Aceptado: 26 de agosto 2020

\begin{abstract}
Resumen: Desde el punto de vista de los estudios del paisaje concebidos en sentido cultural, existe una laguna en lo referido al contexto hispanoamericano. La literatura nos suele remitir a Alexander von Humboldt como el precursor y a la escuela del Río Hudson como mayor exponente. Sin embargo, un estudio crítico de los paisajes culturales previos a la producción de viajes y expediciones científicas podría dar como resultado una nueva aproximación al género del paisaje y a la cartografía del conocimiento de la naturaleza. Este texto propone una aproximación a esas representaciones previas en las que el paisaje
\end{abstract} no era paisaje.

Palabras clave: paisaje, viajes, expediciones, culturas indígenas, normatividad.

\begin{abstract}
There is a gap regarding the Spanish American context from the landscape studies point of view, conceived in a cultural sense. Literature directly refers us to Alexander von Humboldt as the main developer and to the Hudson River school as the greatest exponent. However, a critical study in cultural landscape before the visual production of scientific voyages and expeditions, could result in a new approach to the landscape genre and the mapping of nature. This paper proposes an approach to those previous representations, when the landscape was not a landscape.
\end{abstract}

Keywords: landscape, voyages, expeditions, indigenous cultures, normativity. 


\section{Introducción}

En aquella que ha sido llamada la Era de las Exploraciones se alentaron multitud de viajes científicos, entre cuyos objetivos principales estaba el registro y conocimiento directo de la naturaleza y, por ende, el encuentro con escenas de paisajes desconocidos que también fueron registrados y reinventados. Aunque el paisaje es un género pictórico fuertemente asociado a la sensibilidad del siglo XIX, lo cierto es que desde años antes generó gran interés en los círculos ilustrados, tanto entre los profesionales de las bellas artes como entre los científicos. En un mundo actual inundado de medios de masas, no debemos olvidar que en un momento de recursos reproductivos bastante limitado, en los viajes era imprescindible la presencia de artistas encargados de reproducir-de crear- las primeras imágenes del incipiente relato científico de aquellos nuevos mundos. Si nos detenemos a ver cómo define la Real Academia Española la palabra paisaje («extensión de terreno que se ve desde un sitio» ${ }^{1}$ ) asumimos que, en su definición, la mirada es el factor más importante. Por lo tanto, no hay paisaje donde no exista, necesariamente, la presencia del ser humano que lo crea. Y si, como para Korzybski, el mapa no es el territorio, el paisaje tampoco. Es la mirada del hombre la que determina y define, también la que construye y crea realidades. El componente subjetivo es, como argumenta Milani (2007) defendiendo esa misma relación subjetiva entre el observador y el entorno, inherente al concepto de paisaje. El paisaje, por ende, es un acto intencional. Desde que, en 1925, Sauer publicara The Morphology of Landscape, la teoría del paisaje dio un giro en sentido cultural. Sauer demostró que la naturaleza, en sí, existe con y en la cultura, creando formas de vida y considerando el impacto humano en el paisaje como una manifestación cultural (Leighly, 1963). Por lo tanto, el paisaje no sólo se ve, sino que se crea y se representa. En nuestro país, en las últimas décadas se han abierto nuevas perspectivas desde la historia del arte, siendo muy valiosas, en ese sentido, las aportaciones de Javier Arnaldo (1990) en cuanto a las relaciones entre arte, naturaleza y romanticismo. Por su parte, la filosofía ha hecho sus aportaciones, sobre todo, a través de Javier Maderuelo (2005) que nos acerca al paisaje a través de sus orígenes etimológicos. Maderuelo señala que el término paisaje surgió en el seno del arte de la pintura, estableciendo una relación a través de la mirada del arte. Estos vínculos derivados de la experiencia y su representación han sido definidos

\footnotetext{
${ }^{1}$ Según Diccionario de la lengua española, RAE, $22^{\text {a }}$ edición, 2001.
} 
por Alain Roger (2014) como artealización del paisaje, es decir, la revelación de la naturaleza a través del arte como intermediario, un fenómeno muy característico de la cultura paisajística de los siglos XVIII y XIX, de la que Alexander von Humboldt es heredero, como ya presentamos en una investigación anterior (Garrido, 2018). Humboldt, en su obra Cosmos, trazó un itinerario sobre el progreso del arte del paisaje en las civilizaciones, primando el legado de las obras de pintores paisajistas como Lorrain, Ruysdael y Poussin. Sin embargo, es llamativo que ya en el siglo XIX, el propio Humboldt se lamentara de que no hubiera más producción pictórica realizada por los españoles sobre el paisaje de las regiones tropicales, aseverando que, hasta mediados del siglo XVII, «no se tienen paisajes pintados por artistas sobre el terreno, que reproduzcan el carácter propio de la zona tórrida» (Humboldt, 2011, p. 238).

Con la proliferación de los libros de viaje, las ilustraciones empezaron a ser un elemento necesario para poder transmitir al lector de forma visual lo que se describía en el texto de los viajeros (Muller, 2011). Sin embargo, hay que recalcar que el hallazgo de dibujos originales realizados in situ, durante las exploraciones, es muy poco habitual, ya que éstos se consideraban transitorios y su finalidad era ser trasladados a una obra definitiva y más acabada. Hasta bien avanzado el siglo XVI, no se tiene constancia de la participación de artistas en las exploraciones (Sáenz-López, 2011), las imágenes eran realizadas en Europa, a partir de descripciones de quienes ni siquiera intervenían en el proceso creativo. El resultado, generalmente, era fruto de meras interpretaciones de alguien que nunca había estado familiarizado con los lugares que representaba y se basaba en el recuerdo o la imaginación. Esta era una práctica habitual en la representación de sociedades no europeas como ya demostrara Mason en su excepcional Lives of Images (2001), mientras que el texto se ocupaba de la descripción del terreno visitado, las imágenes penetraban en la imaginación construyendo una realidad en el imaginario social. Así, con el tiempo, las ilustraciones empezaron a convertirse en una parte progresivamente autónoma de los relatos de viaje. En el caso americano, pese a las múltiples expediciones llevadas a cabo por la corona en su intención de modernizar la ciencia española, fue Humboldt quien realizó una hercúlea labor de difusión del paisaje de los trópicos que, tras su viaje científico entre 1799 y 1804, publica su Atlas Pintoresco. Vistas de las Cordilleras y los Monumentos de los Pueblos Indígenas de América (1810), 
una colección de 69 estampas, que acompaña al relato de su expedición y visibiliza los monumentos y sitios americanos. Como han apuntado los estudios visuales humboldtianos, a partir de esa conexión discursiva, el paisaje estético se vincula con lo científico y, a su vez, con el relato de viajes (Baron, 2005; Misch, 2008; Ette, 2008; Lubowski, 2009; Gómez Mendoza y Sanz Herráiz, 2010; Garrido, Rebok y Puig-Samper, 2016). Su obra supone un montaje visual muy poderoso, sin precedentes, en el que se agrupan y desglosan ciencia, estética y sentimiento.

Las migraciones fueron una de las primeras acciones estéticas del hombre, caminar es una forma de otorgar un nuevo significado al territorio y habitar el mundo (Careri, 2002). Estudios como el de Mitchell, han demostrado que el paisaje, en sí, es un proceso en movimiento: «el paisaje circula como un medio de intercambio, un lugar de apropiación visual, o un foco de formación de identidad» (1994, p.1). El paisaje que viaja, es cambiante, como lo es el ser humano. Esos paisajes cambiantes que son aún más dinámicos en el encuentro con distintas culturas, son los que hemos definido como paisajes itinerantes. En los viajes los paisajes y sus creadores circulan, se encuentran, se mueven y, por lo tanto, son itinerantes. Estos paisajes itinerantes de los viajes, expediciones y encuentros coloniales de América, establecen relaciones de poder asimétricas y permanentes. Se dan lugar en las «zonas de contacto» que problematizó Pratt (2010), donde la geografía y la cultura entran en conflicto. En el contexto hispanoamericano, los paisajes itinerantes se sitúan dentro de una auténtica reinvención ideológica de encuentros y desencuentros artísticos en la construcción del espacio.

El punto de partida para que la literatura abriera su mirada a otros espacios, dimensiones y modelos, fue la literatura de viaje. Según Ette, con la proliferación de textos «sin residencia fija» (2008, p. 14) la literatura se puso en movimiento y empezó a viajar. Siguiendo esta misma idea, podemos afirmar que los paisajes también se pusieron en movimiento a partir de la popularización de los viajes, porque los pintores y sus obras empezaron a viajar, creando pinturas que se movían -y aún hoy se mueven- a través del tiempo y del espacio. En el paisaje itinerante, no conforma sólo un objeto que puede ser transportado, sino que su propia práctica artística conlleva valores y actitudes asociadas al viaje, a un modo cambiante de observar y, al fin y al cabo, al movimiento. El análisis del paisaje nos permite no sólo mostrar la acción del hombre a lo largo del tiempo, sino 
reconocer aspectos de nuestra historia en el paisaje actual y pasado, en la naturaleza y en la ruina. En este sentido, la evolución de la pintura de paisaje se puede entender como una expresión de la percepción humana de la naturaleza y sus relaciones cambiantes con el entorno, una cuestión que, en la pintura de viajes, tan vinculada a la percepción de la naturaleza de otros mundos, es especialmente conflictiva. Desde los inicios, existió un interés por conocer las leyes naturales, comprenderlas y representarlas, así que la evolución del paisaje discurrió en paralelo al camino que el hombre trazó al intentar, progresivamente, apropiarse de esa naturaleza. Por lo tanto, en los viajes y expediciones, los vínculos de identidad con el paisaje parten de un intrincado proceso de apropiación, que tuvo mucho que ver, en definitiva, con el movimiento y con la itinerancia. Perla Zusman (2015) ya defendió la idea del papel de la movilidad en la configuración de las ideas geográficas y el diálogo intercultural. Los estudios culturales sobre el paisaje se encuentran con un importante vacío en lo que a las sociedades hispanoamericanas se refieren. Esto es debido a varios motivos que tienen que ver con las siguientes cuestiones: por una parte, el propio concepto de paisaje tradicionalmente europeo tiene mucho que ver con la idea de posesión de la tierra, algo que contrasta con la idea de habitar la naturaleza vinculada a diversas tradiciones indígenas y, por otra parte, de esa misma idea se deriva que en las regiones hispanoamericanas el paisaje no adquiere su forma hasta la llegada de Humboldt. Estas situaciones están, a sí mismo, muy relacionadas con la idea de los paisajes itinerantes que no han encontrado una residencia fija y cuya proliferación es inherente a su naturaleza cambiante, viajera y en movimiento.

\section{La doble conciencia: habitar y poseer}

Las culturas precolombinas debieron tener conciencia propia del paisaje que habitaban, aunque fuese en unos códigos distintos a los que entendemos tradicionalmente como normativos. Según Barbara E. Mundy (1996), a partir de la llegada de los españoles, los artistas indígenas comenzaron a imaginar un nuevo paisaje a través de una «doble conciencia» que integraba progresivamente los cambios en la nueva imagen del territorio, convergiendo esas dos distintas concepciones plásticas y cosmológicas. Esa idea del territorio que los españoles impusieron en América está plasmada en la Real Cédula dada por el rey Felipe II el 25 de mayo de 1577: Instrucción y memoria de las relaciones que 
se han de hacer para la descripción de las Indias. Se podría decir que esta fue una de las primeras formas de apropiación razonada del paisaje a través de la imagen, en donde se habían estipulado unas reglas muy precisas de la información que se debía registrar y mostrar. No sólo se debían registrar los límites geográficos, sino que las instrucciones dejan ver un interés manifiesto en las cuestiones culturales del territorio y sus habitantes. A estas relaciones se las calificaba como «descripciones geográficas», «descripciones de la tierra»o «relaciones topográficas». La administración aprovechaba esta información para controlar el espacio desde la península, aunque, en su realización, también pudieron participar criollos y mestizos, en un intercambio de miradas que dan lugar a representaciones únicas. Estas representaciones son interesantes desde la pluralidad de elementos en un todo. El que ilustra la ciudad de Teutenango -Teotenango- es hoy parte de la memoria que queda sobre la región. El dibujo representa la planta de una ciudad ubicada al pie de un cerro arbolado, cuyo perímetro queda delimitado por una muralla. Los edificios y detalles naturales están representados con bastante detalle y se aprecia un sentido embellecedor en el sombreado de las estructuras arquitectónicas. La imagen fue remitida con la Relación hecha por el corregidor Francisco de Ávila, en cumplimiento de la instrucción dada por el rey Felipe II para la descripción de las Indias [Fig. 1]. 


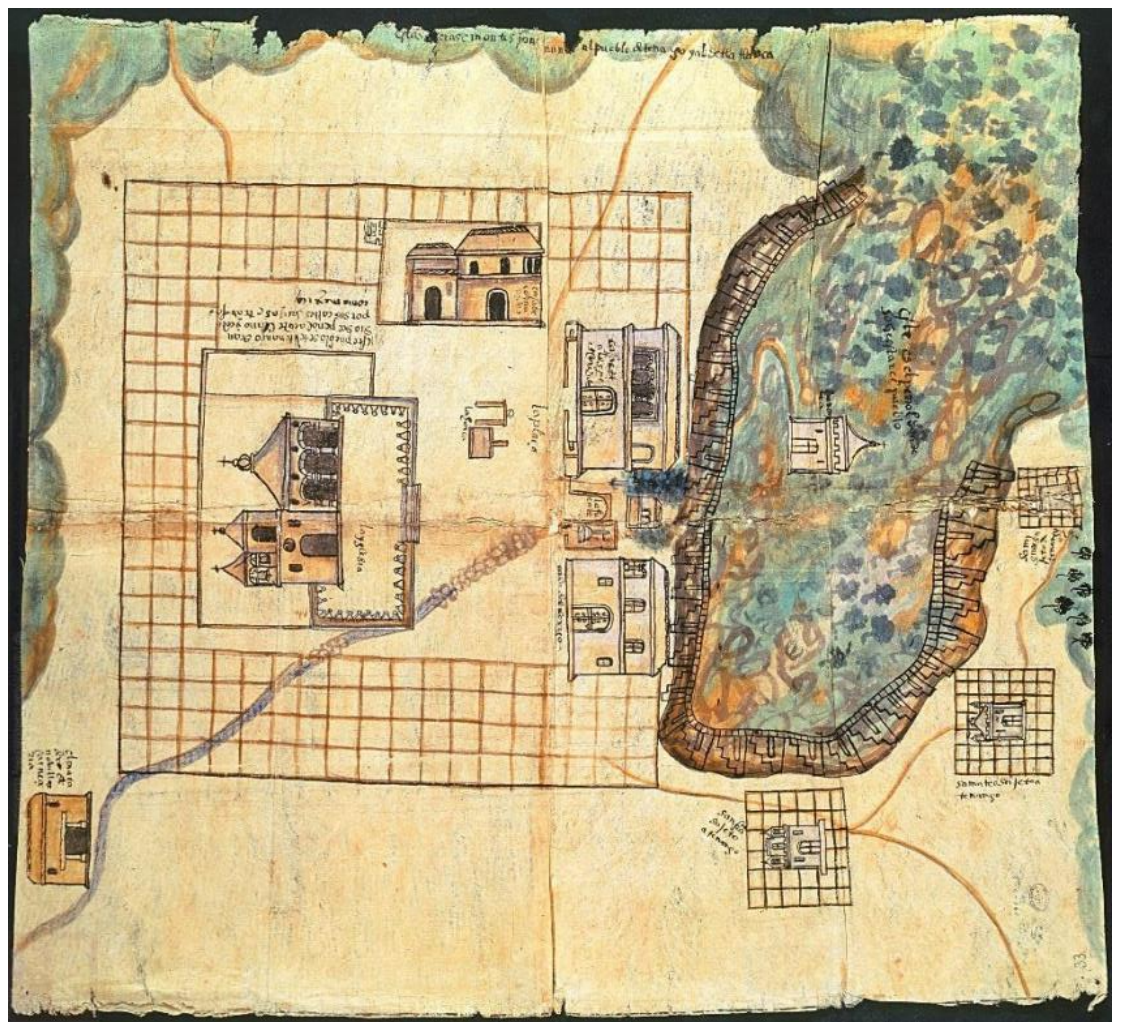

1. Pueblo de Teotenango, en el valle de Matalcingo, en Nueva España, 1582, Archivo General de Indias, Sevilla.

Mientras que la utilidad de la cartografía como elemento de control sigue presente, los límites entre mapa y paisaje se difuminan, conservando no sólo la información sino introduciendo un sentido estético, que incluso podríamos asimilar como precedente primitivo del denominado «cuadro de la naturaleza» humboldtiano (Humboldt, 2003). Este primer ejemplo es una muestra del uso de la imagen para facilitar la apropiación del paisaje de las culturas indígenas. Por otra parte, existen ejemplos que muestran la transmisión forzosa de esa idea de paisaje como posesión de la tierra en los pleitos donde los indígenas se ven obligados a participar para defender sus tierras, Estos ilustran con dibujos visuales datos sobre límites, titularidad y propiedad. Existen trabajos que se han aproximado a este corpus, del que podemos extraer interesante información, como el de Barbara Russo, El Realismo Circular: Tierras, Espacios y Paisajes de la Cartografía Novohispana, siglos XVI y XVII; o el publicado recientemente por Ana Pulido Rull. Mapping Indigenous Land: Native Land Grants in Colonial New Spain (2020). Estos estudios recuperan la presencia indígena en las obras cartográficas, así como las tensiones de poder con la autoridad colonial. Russo y Pulido Rull, atienden especialmente a la 
mediación de lo visual en la cartografía realizada por artistas indígenas, que reproducían cartográficamente sus tierras para defenderlas, analizando las transformaciones del discurso indígena bajo el normativismo colonial, al reivindicar documentalmente los derechos sobre sus propias tierras, de las que habían sido despojados. Estos documentos de pleitos muestran paisajes reales que ponen límites a la tierra -así como un cuadro delimita una vista- y su evolución demuestra una creciente visión artística, con la introducción de elementos como profundidad de campo, perspectiva y composición.

Existen varios ejemplos de pinturas de este tipo, en procesos en los que los artistas eran encargados de ilustrar, visualizar, documentar -he aquí la importancia de la imagen como documento- como apoyo en los procesos judiciales. Paradójicamente, algunos de sus autores fueron indígenas. Estos ejemplos demuestran, visualmente, cómo los espacios de dos culturas muy diferentes tuvieron que reinventarse (Russo, 2005, P. 106). Si hay una diferencia que caracteriza la evolución entre el mapa y el paisaje, es la mirada. Mientras que los mapas tienen una fuerte intención política, delimitando territorios; el paisaje, en el sentido artístico del término, conlleva un sentimiento de la naturaleza que da el placer estético de la belleza que se contempla. Sin embargo, las miradas se entrelazan. En el documento denominado «Pintura de la Costa de Cartaxena» se delimitan las costas en un dibujo que fue parte documental de una investigación sobre contrabando. Se utilizó como complemento al auto del juez de la comisión creada para investigar el contrabando y así lo especifica al dorso, fechado el 17 de abril de 1629. En el texto de la documentación asociada se identifica como «pintura» y no como «carta» o «mapa». Muestra una representación paisajística de la zona, incluyendo parte de la cordillera de los Andes [Fig. 2]. 


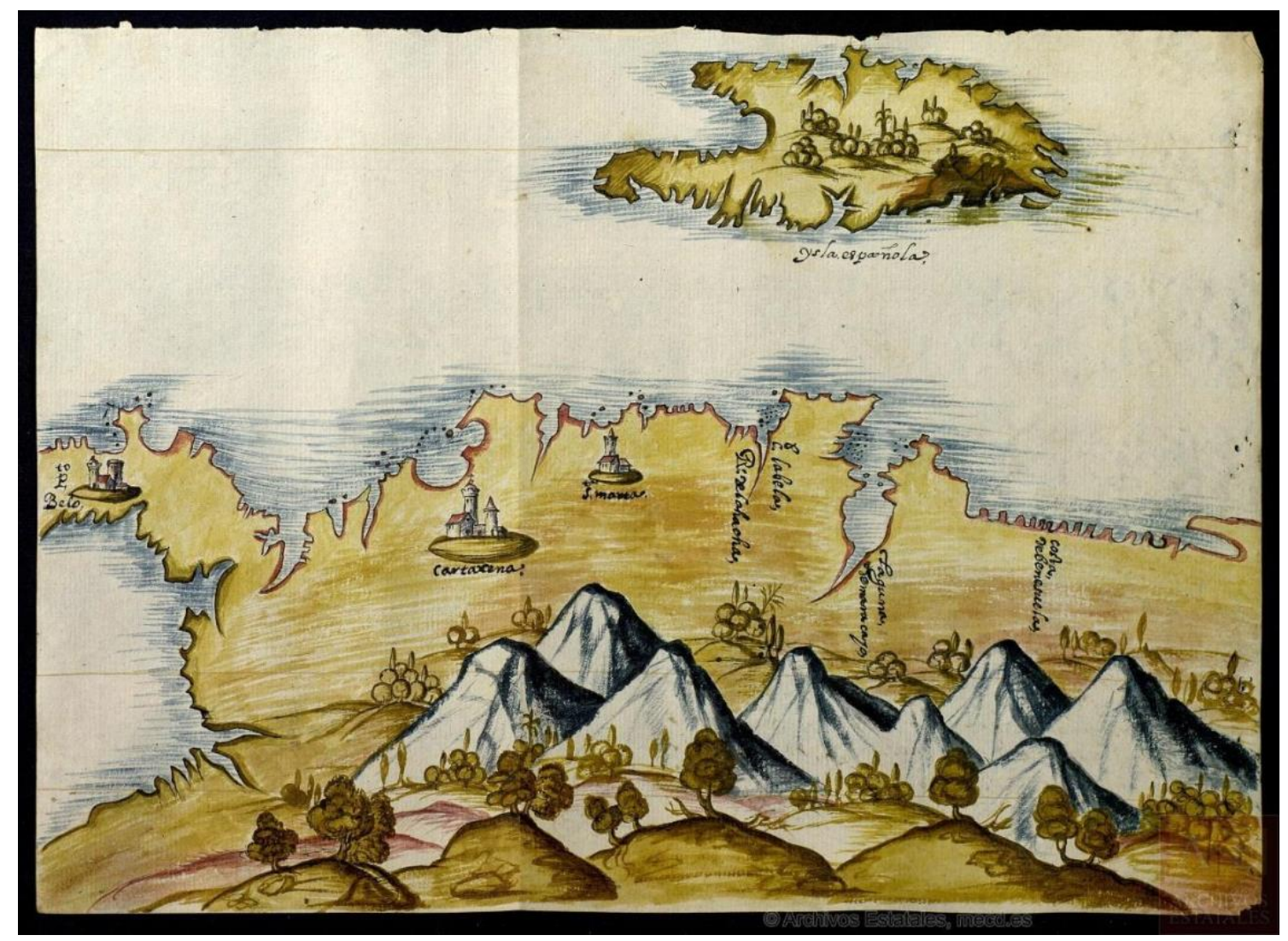

2. Pintura de la Costa de Cartaxena, 17 de abril de 1629, Archivo Histórico Nacional, Madrid.

Diversos estudios ya han demostrado que los mapas pueden situarse plenamente en un contexto de la historia del arte y la evolución de la teoría estética (Sáenz-López, 2014; Harmon, 2010; Woodward, 1987). Obviamente, el paisaje, también llegará a ser un objeto de posesión de la tierra. En particular, en el paisaje pintoresco, con el apogeo de las teorías sobre la percepción de la naturaleza, contiene sus propias formas ideológicas y culturales de apropiación. Cuando las teorías que hacían referencia a los aspectos formales dan el giro hacia la sensibilidad del espectador, las cualidades artísticas dejan de estar en la obra, para situarse en la mirada de quien la observa y la proyecta. En los principios de la belleza pintoresca, que desarrollara William Gilpin en el siglo XVIII, ya estaban presentes en las composiciones de artistas como Nicolas Poussin, Claude Lorrain y Salvatore Rosa, que en sus paisajes acentuaban el valor natural de una escena creada, corroborando esa existencia del cruce mimético entre arte y naturaleza. Pero lo pintoresco es una proyección cultural que excede lo meramente formal; lleva implícitas una serie de ideas sobre la naturaleza y el territorio. Lo pintoresco, más que un estilo, fue la expresión de la nueva sensibilidad que se configuraba en el marco cultural de la Ilustración o, como 
la ha definido Maderuelo, «una forma intelectual bajo la cual los británicos entendieron el mundo, el territorio, el paisaje y la ciudad»(2012, p.79). Mientras se gestaba esa discusión sobre lo pintoresco, numerosos viajeros, artistas y científicos empezaron a captar y poseer paisajes a través de sus vistas a lo largo del mundo. Aquella idea de componer vistas, paisajes y jardines nos revela mucho más sobre lo que significó para los viajeros captar la naturaleza a partir de la visión pintoresca. La transformación del territorio se convertía en una de las artes mayores y con ello, los terratenientes podían disfrutar de poseer una porción de la naturaleza y ejercer su derecho a sentirse propietarios, apreciando y reproduciendo en ella sus ideales, modificando sus formas y convirtiendo el paisaje en su jardín. En la colonización americana, el objetivo era el de poseer y cultivar la tierra, más que el de contemplarla o admirarla (Nygren, 2016, p.18). En ese sentido, como argumenta Bleichmar (2012) el poder virreinal, interesado en la catalogación del territorio, buscaba realizar imágenes que permitirán su conocimiento, pero que también afianzaban ese sentimiento de posesión. Si las representaciones botánicas fueron muestras del poder imperial y la cartografía la visualización de sus posesiones y linderos, las vistas de lo pintoresco legitimaban la posesión de una porción de tierra, su uso y su aprovechamiento, a través de la vista.

\section{El otro paisaje}

En todas las ramas del conocimiento, el descubrimiento de América hizo tambalear los pilares del mundo conocido. En términos de Said, supuso un proceso identitario - yo no soy lo que el otro es o yo soy lo que el otro no es-. Este proceso también afectó a la naturaleza y, por supuesto, al paisaje. Si observamos las formas de representación de la naturaleza indígena, nos encontramos con una idea de territorio que existe, pero cuyo lenguaje dista mucho de ser reconocido por los parámetros tradicionales. Los ejemplos documentales previos a la colonización son escasos, pero existen ciertas obras elaboradas por artistas indígenas que podrían servir para explorar distintas concepciones del paisaje y deberían explorarse en mayor profundidad. Una interesante fuente de información son los códices, como el de Xolotl, que sin poder evitar lo transculturado, muestran la cosmogonía indígena y su reflejo en el territorio [Fig. 3]. 


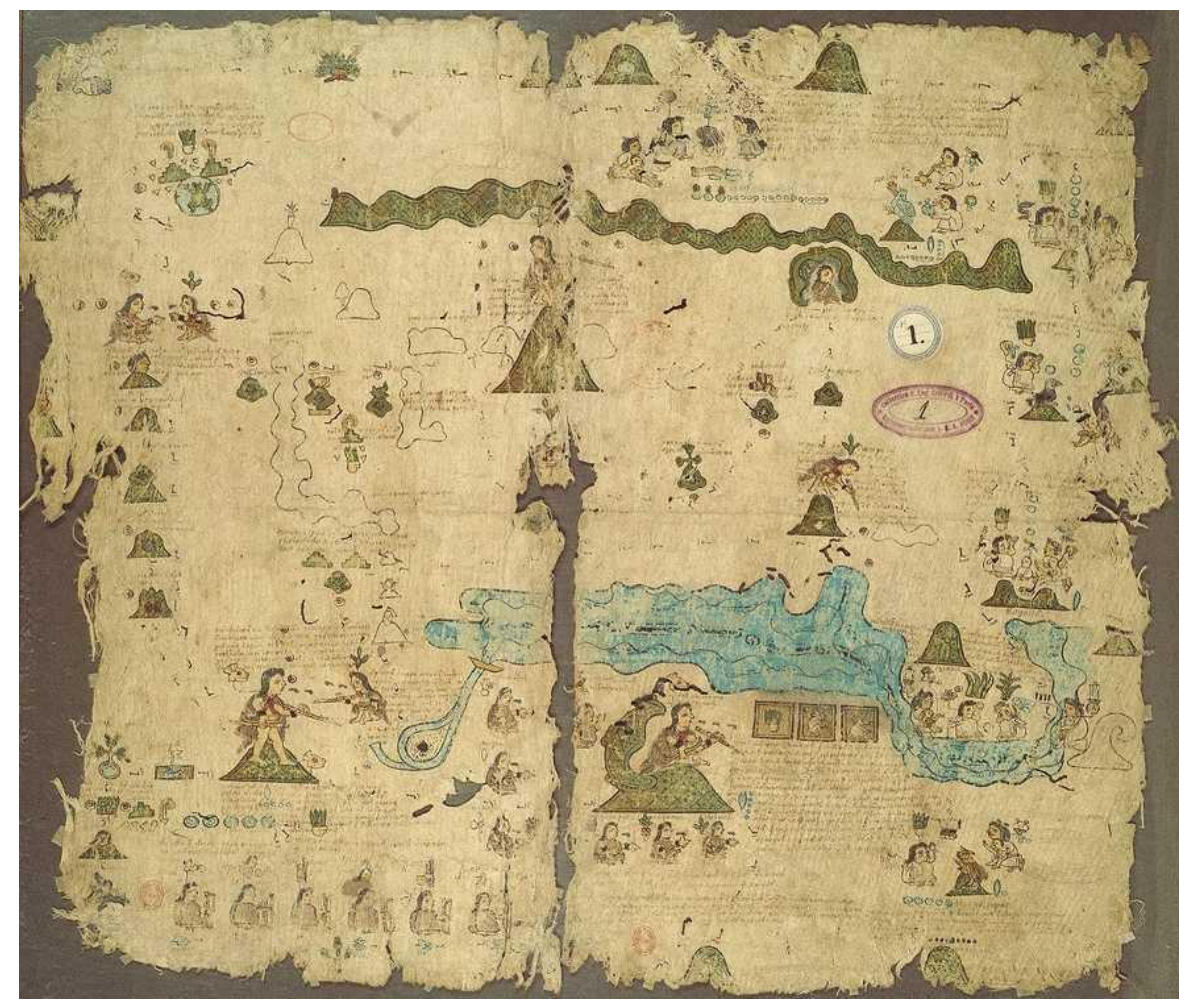

3. Escena del Códex Xolotl. Wikimedia Commons.

Esta obra representativa de la cultura náhuatl en la región de Texcoco, muestra en un cuadro las ideas sobre el universo, la naturaleza y los seres humanos. La escena habla de la forma de entender el territorio y, a su vez, destaca por sus datos geográficos. En la imagen se observa la entrada de Xolotl a la región de los lagos. Abajo al centro, se le ve en el cerro de Tenayuca, rodeado por su mujer (atrás) y sus hijos (abajo), indicando que ha tomado posesión de la tierra. Las huellas de pies señalan el reconocimiento del territorio hecho por Xolotl y su hijo Nopaltzin.

Otra fuente de estudio que muestra datos relevantes son las imágenes de Felipe Guamán Poma de Ayala, un cronista indígena cuya obra era originariamente una carta dirigida al rey de España, donde ponía en evidencia los problemas administrativos en sus dominios americanos. Su obra resulta imprescindible para reflexionar sobre trasculturación y resistencia (Adorno, 1991; Pratt, 2010). En su obra Nueva Cronica y Buen Gobierno, dedica un capítulo a unas particulares vistas de ciudades. En sus ilustraciones se muestran escenas como «La villa de Castrovirreina» y «La villa rica de Oropesa de Guanca Bilca». A través de ellas, podemos conocer algo más sobre la 
percepción del paisaje y la vida en la colonia por parte de los nativos, no sólo a través de la imagen, sino también en anotaciones de las que el autor quiso dejar constancia, al escribir en la segunda de ellas: «En la dicha mina se acaban los indios» [Fig. 4].

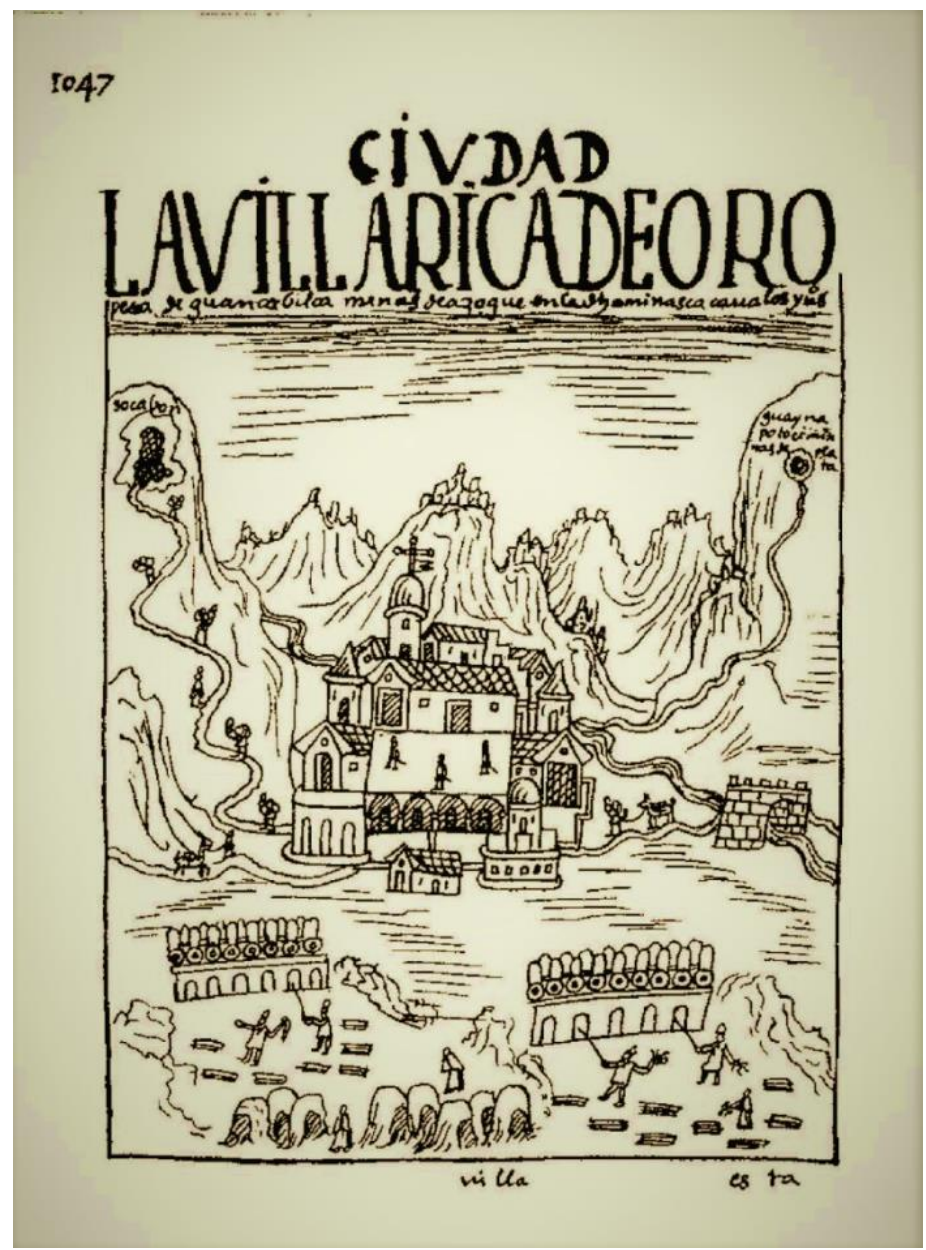

4. Guamán Poma. Dibujo 370. La villa de Oropesa de Guanca Bilca, minas de azogue, 1615. Donde se escribe la leyenda "En la dicha mina se acava los yndios" según Det Kongelige Bibliotek, Copenhague, Dinamarca.

Imágenes como estas deberían hacernos repensar la forma de entender la concepción del espacio y la naturaleza, como el resultado de las distintas acciones del desarrollo de las actividades humanas, es decir, el paisaje. La reconfiguración del discurso no fue equilibrada, pero «el indígena también quería representar su propio espacio vivido con montañas y valles, es decir, real» (Russo, 2005, p. 9). Si Humboldt ha seguido siendo el gran exponente del paisaje americano, es porque obviamos que estas representaciones no componen un paisaje. Humboldt reforzó esa idea en sus textos, asumiendo que el 
paisaje americano nunca se había materializado hasta que pasó por el filtro de las artes europeas:

Para que la representación de las formas individuales de la naturaleza, en lo que se refiere a la rama del arte que nos ocupa, pudiese adquirir mayor variedad y exactitud, era preciso que se hubiera agrandado el círculo de los conocimientos geográficos; que se facilitarán los viajes a las regiones lejanas, y que se ejercitase el sentimiento de comprender las diferentes bellezas de los vegetales y caracteres comunes que los agrupan en familias naturales (...) todas estas causas juntas familiarizaron a los pintores con las formas maravillosas de un gran número de producciones exóticas, y les dieron alguna idea del mundo tropical (Humboldt, 2011, p. 337)

A su vez, erige a Frans Post y Albert Eckhout como los primeros pintores en representar la naturaleza americana en su conjunto, de una forma meritoria en cuanto a conocedores del territorio (Humboldt, 2011, p. 238). Esa idea es la heredada por la investigación tradicional sobre el paisaje americano que, reforzada por la Edad de Oro holandesa, en la que se origina el desarrollo de la tecnología óptica y la observación científica, autoriza sus imágenes como un modo de acercamiento preciso al mundo, convirtiendo a la pintura en un «arte descriptivo» (Alpers, 2003 y 2009). Pese a que algunas expediciones científicas anteriores, enviadas por la corona española como la de Malaspina, ya representaron paisajes en sus registros, Humboldt fue el primero en publicar ese gran atlas pintoresco de América, un museo portátil de lo que no había sido visto nunca antes, dando forma al paisaje del Nuevo Continente en los códigos europeos. Notemos que los paisajes de Humboldt se hicieron más célebres que los objetos y monumentos indígenas. De hecho, como resaltó Pratt (2010) en Vistas de las Cordilleras y monumentos de los pueblos indígenas de América, se perdió casi inmediatamente la segunda parte del título «monumentos», pasando a conocerse generalmente como Vistas, perdiendo la atención sobre tantas reliquias arqueológicas entre las que figuraban la pirámide de Cholula, el calendario azteca, la estatua de una sacerdotisa azteca, jeroglíficos y manuscritos. Paradójicamente, esa operación epistemológica asumía sobre el territorio nuevas formas plásticas que surgían desde la subjetividad de categorías culturales propias. El éxito de su obra se comprende identificándolo como el artífice del desvelamiento de un espacio que ya existía, pero cuya mirada reinventa. Humboldt cumplía con la necesidad de traducir toda esa información diversa a través de una idea de 
totalidad; el arte fue el medio que lo hizo posible. Se podría decir que América había sido representada por fragmentos, como partes de un paisaje que todavía no habían sido representados de forma unitaria. La forma de compensar esa fragmentación era hacer uso de la representación de un todo. Sus imágenes construyen un relato narrativo, sobre diversos lugares, tiempos y culturas, que habían sido presentadas bajo información fragmentada y que se constituían en un solo acto: visualizar el panorama de América.

\section{Conclusiones}

Podríamos decir que hay dos caminos por los que circula la historia del paisaje en el contexto hispanoamericano, que culminan con el éxito y asentamiento de la obra humbodltiana. En primer lugar, los paisajes itinerantes, cuyas representaciones de cánones europeos hablan de poseer y no de habitar. Por otra parte, tenemos ejemplos de paisajes que se habitan, en los que los artistas indígenas dejan su impronta y que pueden esclarecer nuevas perspectivas sobre el paisaje precolonial. No obstante, como se ha referido, estas representaciones son fruto de una doble conciencia impuesta por la llegada de lo ajeno, pero que no difiere de repensar una nueva forma de acercarnos a la investigación del paisaje en las culturas indígenas. Pero ¿podemos afirmar que exista esta noción de paisaje en las culturas indígenas americanas? Estamos ante una carencia conceptual. En todas las sociedades existe entre los seres humanos y su entorno, necesariamente, una relación visual. Eso no quiere decir, según Augustin Berque, que se tenga una noción formada del concepto paisaje, por lo que debemos evidenciar la existencia de ciertas culturas no paisajistas. Los cuatro criterios que propone Berque para la existencia del paisaje son las siguientes: 1 . Representaciones lingüísticas, es decir, una o varias palabras para decir 'paisaje'; 2. Representaciones literarias, orales o escritas, que canten o describan las bellezas del paisaje; 3. Representaciones pictóricas cuyo tema sea el paisaje; y 4. Representaciones jardineras que traduzcan una apreciación estética de la naturaleza. En numerosas sociedades puede encontrarse una u otra de estas condiciones, pero sólo en las sociedades propiamente paisajeras, se encuentran reunidos los cuatro criterios. Para aquellas que no cumplan las citadas condiciones, Berque propone la denominación de protopaisaje. Roger dio un paso más proponiendo reducir la 
adjudicación de protopaisaje sólo a las culturas que reúnan, al menos, uno de aquellos cuatro criterios y que podrían ser clasificadas gradualmente:

«consecuentemente, las sociedades antiguas y las medievales merecen ser llamadas protopaisajeras, puesto que en ellas encontramos jardines (condición 4) y, más o menos, representaciones literarias o pictóricas (condiciones 2 y 3). Se podría incluso plantear una tipología jerarquizada dependiendo del número de condiciones que se cumplen. Toda sociedad productora de jardines de recreo (artealización in situ) sería protopaisajera de grado uno. Cuando se añadan representaciones literarias y/o pictóricas, sería protopaisajera de grado dos o tres. Si, finalmente, aparece el nombre, sería totalmente paisajera» (Roger, 2014, p. 57).

¿Podría asignarse a las culturas precoloniales la noción de "protopaisaje? Es complicado referirlo cuando hablamos de territorios que han sido intervenidos de tal manera, que nos hace reiterar en referirnos a sus representaciones como paisajes itinerantes. De hecho, se considera que la tradición clásica es un referente para el paisaje americano, que termina por alcanzar su plenitud con la llegada del siglo XIX. Los pintores de la River Hudson School progresivamente adaptan los viejos modelos europeos para reinventarse como paisajistas en un sentido de identidad nacional y, así, como pioneros del arte americano, una idea que se ve reforzada por la emergente conciencia de nueva nación, de tierra prometida. Por otra parte, la tradición académica de estudios de este paisaje "americano", se suele referir sólo al norte, excluyendo de esa percepción de la naturaleza identitaria al sur.

Un examen más cuidadoso de las realidades sociales y culturales complejas de las regiones americanas y, particularmente, latinoamericanas, nos tendrían que llevar a desconfiar del arte expresado como una única identidad nacional y obligarnos a reconocer el paisaje en toda su complejidad cultural, asimilando la amplia diversidad de identidades que intervienen en la dinámica entre esos grupos a quienes se aplica el término «indígena». Las comunidades constituyen pequeños universos sociales con su propia organización, costumbres, redes, prácticas culturales, etc. Es posible que una investigación más profunda, tomando como perspectiva los criterios establecidos por Berque puedan ser un punto de partida y, reuniendo mayores datos empíricos a través de diversos estudios antropológicos de casos concretos como los que hemos referido, se 
pueda avanzar considerablemente en la comprensión del modo indígena de pensar el territorio y las diferentes relaciones humanas con el paisaje. Las disciplinas académicas y la geografía que se configuran en el marco de modernidad se nutren de los conocimientos que derivaron de los viajes. Es urgente renovar los estándares para abrir nuevas líneas de investigación sobre el paisaje americano, incluyendo parámetros epistemológicos diversos. Sólo de esa forma se abriría la puerta a la diversidad geográfica y cultural de otras realidades: los otros paisajes.

\section{Referencias bibliográficas}

Adorno, R. (1991). Guamán Poma: literatura de resistencia en el Perú colonial. México: Siglo XXI.

Arnaldo, J. (1990). Estilo y naturaleza: la obra de arte en el romanticismo alemán. Antonio Madrid: Antonio Machado.

Baron, F. (2005). "From Alexander von Humboldt to Frederick Edwin Church. Voyages of Scientific Exploration and Artistic Creativity". Alexander von Humboldt im netz. VI (10), 173-185.

Bleichmar, D. (2012). Visible Empire: Botanical Expeditions and Visual Culture in the Hispanic. Enlightenment. University of. Chicago Press.

Careri, F. (2002). El andar como práctica estética. Barcelona: Gustavo Gili.

Dixon, J. (1991). “Le paysage americain est-il devenu no européen?”, Le Debat, 65.

Ette, O. (2008). Literatura en movimiento. Espacio y dinámica de una escritura transgresora de fronteras entre Europa y América. Madrid: CSIC.

Garrido, E. (2018). Arte y Ciencia en la pintura de paisaje: Alexander von Humboldt. Madrid: Doce Calles.

Garrido, E., Rebok, S., Puig-Saper, M.A. (2016). "El arte al servicio de la ciencia: antecedentes artísticos para la impresión total del paisaje en Alexander von Humboldt", Dynamis, 36 (2), 363-390. 
Gombrich, E. (2000). Art and Illusion. A study in the psychology of pictorial representation. New York: Princeton University Press.

Gómez-Mendoza, J., Sanz Herráiz, C. (2010). "De la biogeografía al paisaje de Humboldt: pisos de vegetación y paisajes andinos equinocciales”, Población y Sociedad, 17 (1), 29-57.

Harmon, K. (2010). The Map as Art: Contemporary Artists Explore Cartography. Princeton University Press.

Humboldt, A.v. (2003). Cuadros de la Naturaleza. Madrid: Los libros de la Catarata.

Humboldt, A.v. (2011). Cosmos. Madrid: CSIC.

Leighly, J. (1963). Land and Life. A selection from the writings of Carl Ortwin Sauer. Berkeley: University of California Press.

Lubowski, A. (2009). The Picture of Nature: Alexander von Humboldt and the Tropical American Landscape. PhD dissertation, Institute of Fine Arts, New York.

Maderuelo, J. (2005). El paisaje. Génesis de un concepto. Madrid: Abada.

Maderuelo, J. (2012). “La mirada pintoresca”, Quintana, 11, 79-90.

Mason, P. (2001). The lives of images. Londres: Reaktion Books.

Milani, R. (2007) El arte del paisaje. Madrid: Biblioteca Nueva.

Mitchell, W.J.T. (1994). Landscape and Power. Londres: Routledge.

Misch, J. "Ciencia y Estética. Reflexiones en torno a la presentación científica y la representación artística de la naturaleza en la obra de Alejandro von Humboldt”. En M. Cuesta y S. Rebok (eds.) Alexander von Humboldt. Estancia en España y viaje americano. Madrid: RSG-CSIC, 279-298.

Muller, C. (2011) "Los diarios de viajes y las Bellas Artes. Del dibujo ilustrador a la obra artística autónoma”. En R. Musser (ed.). El viaje y la percepción del otro: viajeros por la 
península ibérica y sus descripciones (siglos XVIII y XIX). Madrid: Iberoamericana Vervuert, 109-118.

Mundy, B. (1996). The Mapping of New Spain. Indigenous Cartography and the Maps of the Relaciones Geográficas. University of Chicago Press.

Nygren, E.J. (1986). Views and Visions: American Landscape before 1830. Washington D.C.: The Corcoran Gallery of Art.

Pratt, M.L. (2010). Ojos imperiales: literatura de viaje y transculturación. Mexico: FCE.

Pulido Rull, A. (2020). Mapping Indigenous Land: Native Land Grants in Colonial New Spain. University of Oklahoma Press.

Roger, A. (2014). Breve tratado del paisaje. Madrid: Biblioteca Nueva.

Russo, A. (2005). El Realismo Circular: Tierras, Espacios y Paisajes de la Cartografía Novohispana, siglos XVI y XVII. Mexico: UNAM.

Sáenz-López, S. (2014). Los mapas de los beatos: la revelación del mundo en la Edad Media. Burgos: Siloé.

Sáenz-López, S. (2011). "Las primeras imágenes occidentales de los indígenas americanos: entre la tradición medieval y los inicios de la antropología moderna", Anales de Historia del Arte, 1, 463-481.

Woodward, D. (1987). Art and Cartography: Six Historical Essays. New York: Princeton Architectural Press.

Zusman, P. (2015). "No solo el reposo configura geografías", Terra Brasilis [En línea], Acceso: 23 abril de 2020. URL: http://journals.openedition.org/terrabrasilis/1367 
